\title{
PENGARUH PIJAT BAYI SEBAGAI TERAPI KOMPLEMENTER TERHADAP KONSTIPASI PADA BAYI 6-12 BULAN
}

\author{
Niluh Ayu Parasita ${ }^{1}$, Ika Arum Dewi ${ }^{2^{*}}$, Wira Daramatasia ${ }^{3}$
}

1,2,3STIKES Widyagama Husada Malang

*Corresponding author:

Ika Arum Dewi

STIKES Widyagama Husada Malang

Email: ikaarumds@gmail.com

\begin{abstract}
Background: Constipation is a condition that is often found in children characterized by a decrease in the frequency of defecating less than three times a week and anxiety during the defecation process due to pain during bowel movements. As much as $48 \%$ of babies suffer from chronic constipation in Indonesia. This condition needs to be treated appropriately because it can cause discomfort and nutritional problems for the baby. One of the treatments for constipation is to use non-pharmacological therapies such as baby massage. This study aims to determine the effect of infant massage as a complementary therapy on constipation in infants aged 6-12 months at Puskesmas Mojolangu - Malang City. Methods: This study used a Quasy Experiment method with a desaign pre-post control group conducted on 24 infants aged 6-12 years who experienced constipation. The sample was divided into 12 groups and 12 treatment control groups using the observation sheet as a research instrument. Results: Based on research that has been conducted using the Wilcoxon test, the value of $p=0.002$ is obtained so that H1 shows that there is a significant effect of infant massage therapy on constipation in infants aged 6-12 months at the Puskesmas Mojolangu - Malang City. Conclusion: Infant massage as a complementary therapy is effective in overcoming constipation problems in infants aged 6-12 months at Puskesmas Mojolangu - Malang City

Keywords: Constipation; infant massage; infants aged 6-12 months.
\end{abstract}

\begin{abstract}
Abstrak
Latar Belakang: Konstipasi merupakan keadaan yang sering ditemukan pada anak yang ditandai dengan penurunan frekuensi Buang Air Besar kurang dari tiga kali dalam satu minggu dan terjadi kecemasan ketika proses defekasi karena nyeri saat buang air besar. Sebesar $48 \%$ bayi menderita konstipasi kronis di Indonesia Kondisi ini perlu ditangani secara tepat karena dapat menyebabkan ketidaknyamanan dan masalah gizi pada bayi. Salah satu penanganan konstipasi tersebut adalah dengan menggunakan terapi nonfarmakologi seperti pijat bayi. Penelitian ini bertujuan untuk mengetahui adanya pengaruh pijat bayi sebagai terapi komplementer terhadap konstipasi pada bayi usia 6-12 bulan di Puskesmas Mojolangu - Kota Malang. Metode: Penelitian ini menggunakan metode Quasy Eksperiment dengan pre-post control group desaign yang dilakukan pada 24 bayi usia 6-12 tahun yang mengalami konstipasi. Sampel dibagi menjadi 12 kelompok dan 12 kelompok kontrol perlakuan dengan menggunakan lembar observasi sebagai instrument penelitian. Hasil: Berdasarkan penelitian yang telah dilakukan menggunakan Uji Wilcoxon didapatkan nilai $\mathrm{p}=0.002$ sehingga $\mathrm{H} 1$ menunjukkan bahwa terdapat pengaruh bermakna dari terapi pijat bayi terhadap konstipasi pada bayi usia 6-12 bulan di Puskesmas Mojolangu - Kota Malang. Kesimpulan: Pijat bayi sebagai terapi komplementer efektif dalam mengatasi masalah konstipasi pada bayi usia 6-12 bulan di Puskesmas Mojolangu - Kota Malang Kata Kunci: Konstipasi; pijat bayi; bayi usia $6-12$ bulan.
\end{abstract}




\section{PENDAHULUAN}

Konstipasi merupakan defekasi yang tidak lebih sering dari tiga hari sekali. Pada anak normal, konsistensi feses dan frekuensi BAB dapat berbeda-beda. Gejala sulit buang air besar yang dengan konsistensi feses keras, ukuran besar, dan penurunan frekuensi buang air besar. Berdasarkan patofisiologi, konstipasi diklasifikasikan atas konstipasi akibat kelainan organik dan konstipasi fungsional (Iacono, 2014.)

Prevalensi konstipasi pada anak diperkirakan o,3\%8\%.3 Hal ini sesuai dengan penelitian studi retrospektif oleh LeoningBaucke pada tahun 2015 didapatkan 2,9\% prevalensi konstipasi pada usia anak sampai 1 tahun dan meningkat pada tahun kedua, yaiu sekitar 10,1\%.4 Data prevalensi di Indonesia tercatat $73,2 \%$ anak mengalami masalah pencernaan yakni sembelit dan diare. Penelitian yang dilkukan oleh setiawan (2016) menyatakan bahwa $48 \%$ bayi mengalami konstipasi kronis (Seiawan, 2016)

Konstipasi pada anak dimulai dari rasa nyeri saat buang air besar. Karena nyeri saat buang air besar biasanya anak mulai menahan-nahan tinja agar tidak dikeluarkan untuk menghindari rasa tidak nyaman atau nyeri tersebut. Jika menahannahan buang air besar terus berlanjut, maka keinginan buang air besar akan berangsur hilang yang akan mengakibatkan penumpukan tinja. Proses buang air besar yang tidak lancer akan menyebabkan tinja menumpuk hingga menjadi lebih banyak dari biasanya dan dapat menyebabkan feses mengeras yang kemudian dapat berakibat pada spasme sfingter anus. Distensi rectal kronik menyebabkan kehilangan sensitifitas rektal, keinginan defekasi yang dapat berdampak pada inkontinensi afekal ( Suarsyaf1 ,2015).

Konstipasi merupakan keadaan yang sering ditemukan pada anak, dan dapat menimbulkan masalah sosial maupun psikologis. Sering ditandai dengan cemas ketika defekasi karena nyeri saat buang air besar. Berdasarkan kondisi patofisiologis konstipasi diklasifikasikan menjadi konstipsi fungsional dan konstipasi akibat kelainan struktural. Menurutthe North American Society for Pediatric Gastroenterology and Nutrition (NASPHGAN), konstipasi adalah kesulitan atau keterlambatan melakukan defekasi selama dua minggu atau lebih dan mampu menyebabkan stress pada pasien.

Konstipasi dapat terjadi karena ibu memberikan makanan padat dan tidak memberikan ASIsehingga bayi mengalami gangguan saluran pencernaan dan kekurangan cairan. Apabila tidak tertangani dengan baikkonstipasi yang berat atau cukup hebat dapat terjadi obstipasi. Obstipasi ini dapat menyebabkan kanker usus yang berakibat membahayakan bagi bayi dan balita. (Wulandari, 2016).

Keluhan konstipasi sering menjadi alasan orang tua mengajak anaknya berobat. Konstipasi tidak dipengaruhi oleh status sosial, ekonomi, dan jumlah anak. Penanganan konstipasi dilakukan dengan terapi farmakologi maupun non farmakologi. Terapi farmakologi dengan pemberian obat laksatif sedangkan terapi non farmakologi dengan diit dan perubahan perilaku. Salah satu terapi non farmakologi pada konstipasi adalah dengan terapi pijat. (Wulandari, 2016).

Pijat merupakan terapi sentuhan yang dikenal sejak berabad-abad silam. Bahkan terapi ini sudah dikenal sejak awal manusia ada di dunia. Laporan mengenai seni pijat untuk pengobatan tercatat di Papyrus Ebers, yaitu catatan kedokteran pada zaman Mesir Kuno. Di India juga ditemukan Ayur Veda, buku kedokteran tertua (sekitar tahun 1.800 sebelum masehi) menuliskan tentang terapi pijat, diet dan olahraga pada masa itu. Selain itu, sekitar 5.000 tahun yang lalu, para dokter di China dari dinasti Tang meyakini bahwa pijat adalah salah satu dari empat teknik pengobatan yang penting.

Terapi pijat sudah dilakukan sejak jaman nenek moyang. Pijat bayi sendiri merupakan seni perawatan kesehatan bayi dengan terapi sentuh dengan teknik-teknik tertentu sehingga bermanfaat bagi kesehatan bayi. Beberapa penelitian tentang terapi pijat bayi banyak dilakukan dan memberikan dampak yang baik bila 
dihubungkan dengan kondisi dan penyakit pada anak. Salah satu manfaat dari terapi pijat antara lain melancarkan peredaran darah, pencernaan dan pertumbuhan. Handajani menyatakan bahwa, "Terdapat manfaat yang nyata dari pijat bayi yang dilakukan terhadap anak usia 0-12 bulan". Serta didukung Penelitian medis yang telah membuktikan banyak manfaat dari pijat bayi dan balita (Zeevenhooven, Koppen, and Benninga 2017).

Pengalaman pijat pertama yang dialami manusia ialah pada waktu dilahirkan, yaitu pada waktu melalui jalan lahir si ibu. Proses kelahiran adalah pengalaman traumatik bagi bayi karena bayi yang lahir harus meninggalkan rahim yang hangat, aman dan nyaman, dan dengan keterbatasan ruang gerak menuju ke suatu dunia dengan kebebasan gerak tanpa batas, menakutkan, tanpa sentuhan-sentuhannyaman dan aman di sekelilingnya, seperti halnya ketika berada di dalam rahim (McClurg $D$,

\section{Lowe-Strong A. 2011).}

Studi menemukan tentang mekanisme efek pijat bayi terhadap perubahan fisiologikal dan biokimiawi untuk meningkatkan pertumbuhan, meliputi peningkatan aktivitas vagusselanjutnya akan mempengaruhi pelepasan hormon pencernaan seperti gastrin, insulin dan InsulinGrowth Factor (IGF-1) serta meningkatkan efisiensi proses metabolik tubuh (. Jurnalis et al 2013).

Studi pendahuluan yang dilakukan di Puskesmas Mojolangu pada bulan April 2018 terdapat 179 balita di Puskesmas Mojolangu, Kota Malang dan 72 diantaranya mengalami konstipasi tercatat mulai bulan Januari 2018.Sehubungan dengan uraian di atas sehingga peneliti tertarik untuk meneliti tentang hubungan pijat bayi sebagai terapi komplementer terhadap konstipasi yaitu dengan judul penelitian "Pengaruh Pijat Bayi Sebagai Terapi Komplementer Terhadap Konstipasi Pada Bayi Usia 6-12 Bulan di Puskesmas Mojolangu, Kota Malang".

\section{METODE}

Penelitian ini menggunakan desain quasy experimental dengan pendekatan pretest posttest control group design. Pengambilan sampel dilakukan dengan cara memberi lembar observasi (pre-test) kepada semua orang tua bayi usia 6-12 bulan. Teknik sampling menggunakan purposive sampling dengan Pengambilan sampel dilakukan dengan cara memberi lembar observasi (pre-test) kepada semua orang tua bayi usia 6-12 bulan. Sampel penelitian ini adalah 24 bayi yang mengalami konstipasi yang dibagi menjadi 12 kelompok control dan 12 kelompok perlakuan. Penelitian ini dilakukan selama 4 minggu pada periode Juni-Juli 2018. Variabel penelitian adalah pijat bayi sebagai variabel independen dan bayi usia 6-12 bulan yang mengalami konstipasi sebagai variabel dependen. Alat ukur menggunakan Bristol Tool Chart. Uji statistik yang digunakan adalah uji Wilcoxon Sign Rank.

Penelitian dilakukan dengan waktu 2 minggu yang dibagi menjadi beberapa tahap yaitu; melakukan pretest melalui lembar observasi untuk menilai bayi konstipasi atau tidak, dilanjutkan dengan pemberian terapi komplementer dengan pijak bayi (3 pertemuan dalam satu minggu), masing-masing pertemuan berdurasi 30 menit. Kegiatan berikutnya yakni post test melalui lembar observasi untuk menilai apakah bayi masih konstipasi atau tidak. Dari data yang diperoleh, peneliti melakukan analisa tentang adanya pengaruh pijat bayi sebagai terapi komplementer bayi usia 6-12 bulan yang mengalami konstipasi.

\section{HASIL DAN PEMBAHASAN}

Tabel 1. Karakteristik Responden

\begin{tabular}{lcc}
\hline Variabel & $\begin{array}{c}\text { Jumlah } \\
(\mathbf{n})\end{array}$ & $\begin{array}{c}\text { Prosentase } \\
(\mathbf{\%})\end{array}$ \\
\hline Usia & & \\
6 bulan & 4 & 16.7 \\
7 bulan & 3 & 12.5 \\
8 bulan & 6 & 25.0 \\
\hline 9 bulan & 3 & 12.5 \\
\hline 10 bulan & 1 & 4.2 \\
\hline 11 bulan & 3 & 12.5 \\
\hline 12 bulan & 4 & 16.7 \\
\hline Jenis Kelamin & & \\
Laki-laki & 8 & 33.3
\end{tabular}




\begin{tabular}{lcc} 
Perempuan & 16 & 66.7 \\
\hline Jenis Makanan & & \\
Makanan instan & 13 & 54.2 \\
Makanan yang dimasak & 11 & 45.8 \\
sendiri & & \\
\hline Jumlah cairan/hari & & \\
$<1150$ cc & 14 & 58.3 \\
$>1300 \mathrm{cc}$ & 10 & 41.7 \\
\hline
\end{tabular}

Hasil penelitian terhadap responden bayi yang mengalami konstipasi di Puskesmas Mojolangu, Kota Malang berdasarkan usia, mayoritas responden berusia 8 bulan berjumlah $6(25.0 \%)$. Berdasarkan karasteristik jenis kelamin, mayoritas bayi berjenis kelamin perempuan berjumlah 16 (66.7\%) bayi.

Masa bayi antara usia 6-12 bulan merupakan masa emas untuk pertumbuhan dan perkembangan anak. Usia anak usia 6-12 bulan merupakan periode kritis pertumbuhan balita, kebutuhan gizi pada anak usia 6 bulan meningkat dan terdapat adaptasi sistem saluran pencernaan . Penelitian Tunc, Weafer, Corazziari, dan Myo-khin ditemukan bahwa semakin bertambah usia, frekuensi buang air besar semakin berkurang. Hal ini dapat terjadi karena proses kematangan saluran cerna dan asupan makanan. Kondisi ini memicu beberapa masalah pencernaan pada bayi salah satunya adala konstipasi. (Rochsitasari dkk, 2011)

Hasil penelitian terhadap jenis makanan yang dikonsumsi bayi yang mengalami konstipasi didapatkan $13(54.2 \%)$ bayi yang mengkonsumsi makanan instant. Aneka jenis makanan jadi dan makanan siap saji yang tersedia dan mudah diperoleh, dapat memudahkan memilih variasi pangan sesuai dengan selera dan daya beli masyarkat terutama pada daerah perkotaan. Asupan serat yang terlampau rendah dalam waktu lama akan mempengaruhi kesehatan. Menurut Depkes RI tahun 2008, rata-rata konsumsi serat penduduk Indonesia secara umum yaitu $10.5 \mathrm{~g}$ /hari.Nilai ini hanya mencapai setengah dari kebutuhan serat yang dianjurkan. Nilai kebutuhan serat yang dibutuhkan berdasarkan Angka Kecukupan Gizi untuk orang dewasa adalah $38 \mathrm{~g} / \mathrm{hari}$ untuk laki-laki dan 30-32 hari untuk perempuan. Factor resiko asupan serat yang rendah dapat menyebabkan masa feses berkurang dan sulit BAB (Lee dkk, 2008).

Beberapa factor yang mempengaruhi defekasi dan konsistensi feses pada bayi, misalnya jenis susu (ASI PASI), MP - ASI (konsistensi, berserat atau tidak), toilet traning sebelum waktunya. Penelitian yang dilakukan oleh Mayriza (2016) menunjukkan bahwa terdapat hubungan antara asupan serat dengan kejadian konstipasi. Penelitian oleh Rochita (2011), terdapat hubungan antara ketidak cukupan asupan serat makanan dengan konstipasi. Hal ini membuktikan bahwa asupan serat makanan yang sesuai dengan kecukupan asupan serat perhari dapat mengurangi resiko konstipasi.

Hasil penelitian ini menyatakan bahwa mayoritas bayi yang mengalami konstipasi adalah bayi yang mengkonsumsi makanan instan dengan jumlah 13 (54.2\%) bayi. Hal ini dikarenakan makanan instan tidak mudah diserap oleh bayi karena mengandung bahan pengawet dan kurangnya asupan serat dari makanan instan itu sendiri.

Hasil penelitian terhadap jumlah cairan yang masuk didapatkan 14 (58.3\%) bayi dengan jumlah cairan yang masuk ,1150 cc perhari. Asupan cairan merupakan seluruh cairan yang masuk ke dalam tubuh berupa minuman maupun makanan. Air merupakan pelumas yang membantu sisa metabolisme bergerak disepanjang kolon. Tubuh akan selalu membutuhkan air untuk menyerap kembali air yang tersedia di dalam usus ( Claudina, 2018).

Penelitian yang dilakukan di SMA Kesatrian 1 Semarang didapatkan hasil bahwa asupan cairan yang tidak mencukupi berkaitan dengan kejadian konstipasi. Hasil penelitian tersebut sebanyak 49 (67.1\%) responden yang tergolong kurang dalam mengkonsumsi asupan cairan. Penelitian ini sejalan dengan penelitian yang dilakukan di Taman Kanak-kanak di Denpasar yang menunjukkan bahwa asupan cairan yang tidak mencukupi berkaitan dengan kejadian konstipasi ( Claudina, 2018) 
Pada penelitian ini didapatkan mayoritas bayi yang mengalami konstipasi asupan cairan $<1150$ cc sebanyak 14 (58.3\%)bayi, hal ini dikarenakan produksi cairan yang sedikit maka feses akan menjadi kering dari normal dan menghasilkan feses yang mengeras. Hal ini karena air memiliki peran di dalam tubuh yaitu membantu kerja organ-organ pencernaan seperti usus besar yang berfungsi untuk mencegah konstipasi dengan gerakangerakan di dalam usus akan menjadikan feses yang keluar menjadi lebih lancar(Amry, 2013)

Tabel 2. Hasil Analisis Bivariat Pengaruh Pijat Bayi Sebagai Terapi Komplementer Terhadap Konstipasi Pada Bayi Usia 6-12 bulan

\begin{tabular}{|c|c|c|c|c|c|}
\hline \multirow[b]{2}{*}{ NO } & \multirow[b]{2}{*}{ Uraian } & \multicolumn{2}{|c|}{ Pretest } & \multicolumn{2}{|c|}{ Posttest } \\
\hline & & $\begin{array}{c}\text { Jumlah } \\
(\mathbf{N})\end{array}$ & $\%$ & $\begin{array}{c}\text { Jumlah } \\
\text { (N) }\end{array}$ & $\%$ \\
\hline \multirow[t]{4}{*}{1} & Frekuensi BAB & & & & \\
\hline & a. $<3 \mathrm{x} /$ minggu & 12 & 100 & 8 & 66.7 \\
\hline & b. $>3 \mathrm{x} / \mathrm{minggu}$ & 0 & 0 & 4 & 33.3 \\
\hline & Jumlah & 12 & 100 & 12 & 100 \\
\hline \multirow[t]{4}{*}{2} & $\begin{array}{l}\text { Perut teraba } \\
\text { keras }\end{array}$ & & & & \\
\hline & Iya & 10 & 83.3 & 7 & 58.3 \\
\hline & Tidak & 2 & 16.7 & 5 & 41.7 \\
\hline & Jumlah & 12 & 100 & 12 & 100 \\
\hline \multirow[t]{10}{*}{3} & Type Feses & & & & \\
\hline & Tipe 1 & 6 & 50.0 & 4 & 33.3 \\
\hline & Tipe 2 & 6 & 50.0 & 5 & 41.7 \\
\hline & Tipe 3 & & & 1 & 8.3 \\
\hline & Tipe 4 & & & 2 & 16.7 \\
\hline & Tipe 5 & & & & \\
\hline & Tipe 6 & & & & \\
\hline & Tipe 7 & & & & \\
\hline & Jumlah & 12 & 100 & 12 & 100 \\
\hline & Uji Wilcoxcon & P valu & $=0,014$ & & \\
\hline
\end{tabular}

Hasil penelitian pada tabel 5.2 menunjukkan hasil pada bayi dengan kelompok control pada pretest didapatkan 12 bayi dengan frekuensi $\mathrm{BAB}<3 \mathrm{x}$ dalam seminggu, 10 bayi dengan perut teraba keras, 6 bayi dengan tipe feses 1 dan 6 bayi dengan tipe feses 2. Dan pada posttest di dapatkan $8(66.7 \%)$ bayi dengan frekuensi $\mathrm{BAB}<3 \mathrm{x} / \mathrm{minggu}, 7$ (41.7\%) bayi dengan perut yang teraba keras, 4 (33.3\%) bayi dengan feses tipe 1 dan 5 (41.7\%) bayi dengan feses tipe 2 .

Analisis pengaruh pijat bayi sebagai terapi komplementer terhadap bayi usia 6-12 bulan pada kelompok kontrol di Puskesmas Mojolangu memiliki significancy $0.014 \quad(>0.005)$ artinya tidak terdapat pengaruh bermakna pada bayi yang mengalami konstipasi tanpa diberikan terapi pijat. Konstipasi merupakan masalah pencernaan yang biasa terjadi pada bayi dalam masa pertumbuhan, hal ini dipengaruhi oleh perubahan anaotomi fisiologi sistim salauran ceran dan pemberian MPASI. Kondisi ini dapat berdampak pada gangguan nutrisi pada bayi dan infesksi pada saluran pencernaan.

Tabel 3. Hasil Analisis Bivariat Pada Pretest\&Posttest kelompok perlakuan

\begin{tabular}{|c|c|c|c|c|c|}
\hline \multirow[b]{2}{*}{ NO } & \multirow[b]{2}{*}{ Uraian } & \multicolumn{2}{|c|}{ Pretest } & \multicolumn{2}{|c|}{ Posttest } \\
\hline & & $\begin{array}{c}\text { Jumlah } \\
(\mathbf{N})\end{array}$ & $\begin{array}{c}\text { Prosen } \\
\text { tase }\end{array}$ & $\begin{array}{c}\text { Jumlah } \\
(\mathrm{N})\end{array}$ & $\begin{array}{l}\text { Prose } \\
\text { ntase }\end{array}$ \\
\hline \multirow[t]{4}{*}{1} & Frekuensi BAB & & & & \\
\hline & $<3 \mathrm{x} /$ minggu & 12 & 100 & 0 & 0 \\
\hline & $>3 \mathrm{x} /$ minggu & 0 & 0 & 12 & 100 \\
\hline & Jumlah & 12 & 100 & 12 & 100 \\
\hline \multirow[t]{4}{*}{2} & $\begin{array}{l}\text { Perut teraba } \\
\text { keras }\end{array}$ & & & & \\
\hline & Iya & 10 & 83.4 & 1 & 8.3 \\
\hline & Tidak & 2 & 16.6 & 11 & 91.7 \\
\hline & Jumlah & 12 & 10 & 12 & 100 \\
\hline \multirow[t]{10}{*}{3} & Type Feses & & & & \\
\hline & Tipe 1 & 5 & 41.7 & 1 & 8.3 \\
\hline & Tipe 2 & 7 & 58.3 & 1 & 8.3 \\
\hline & Tipe 3 & & & 10 & 83.4 \\
\hline & Tipe 4 & & & & \\
\hline & Tipe 5 & & & & \\
\hline & Tipe 6 & & & & \\
\hline & Tipe 7 & & & & \\
\hline & Jumlah & 12 & 100 & 12 & 100 \\
\hline & Uji Wilcoxon & Pval & 0.002 & & \\
\hline
\end{tabular}

Table 3 menunjukkan hasil Pada bayi dengan kelompok perlakuan sebelum diberikan terapi pijat bayi didapatkan 12 (100\%) bayi dengan frekuensi $\mathrm{BAB}<3 \mathrm{x}$ dalam seminggu, $10(83,4)$ bayi dengan perut yang teraba keras, 5 (41.7\%) bayi dengan tipe feses 1 dan 7 (58.3\%) bayi dengan tipe feses 2 . Dan setelah diberikan terapi didapatkan $12(100 \%)$ bayi dengan frekuensi $\mathrm{BAB}>3 \mathrm{x}$ dalam seminggu, $1(8.3 \%)$ bayi dengan perut yang teraba keras, $1(8.3 \%)$ bayi dengan feses tipe 1 , dan $1(8.3 \%)$ bayi dengan feses tipe 2 .

Analisis pengaruh pijat bayi sebagai terapi komplementer terhadap bayi usia 6-12 bulan di Puskesmas Mojolangu memiliki significancy 0.002 $(<0.005)$ artinya terdapat pengaruh bermakna antara terapi komplementer pijat bayi dengan konstipasi. Konstipasi merupakan gangguan defekasi atau berkurangnya frekuensi buang air besar disertai dengan 
perubahan konsistensi tinja. Menurut Paris Consensus on Childhood Constipation Terminology menjelaskan bahwa defekasi yang terganggu selama 8 minggu minimal 2 gejala sebagai berikut : defekasi kurang dari $3 x$ perminggu, masa tinja yang keras, masa tinja teraba di abdomen, perilaku menahan defekasi, nyeri saat defekasi. Gejala dan tanda klinis konstipasi pada anak dimulai dari rasa nyeri saat defekasi, anak akan mulai menahan tinja agar tidak dikeluarkan untuk menghindari rasa tidak nyaman yang berasal dari defekasi dan terus menahan defekasi maka keinginan defekasi akan berangsur hilang oleh karena kerusakan sensorik di kolon dan rectum sehingga akan terjadi penumpukkan tinja (Wang, 2015). Penanganan konstipasi pada bayi dapat dilakukan dengan memberikan terapi komplementer yaitu pijat bayi.

Terapi pijat bayi telah dibuktikan berpengaruh pada bayi yang mengalami konstipasi. Menurut Underdown dalam dari Warwick medical school, Institute of Education dan Universitas Warwick Coventry menyatakan bahwa pemijatan pada bayi dan balita dapat meningkatkan kesehatan fisik dan ketahanan mentalnya (Xu et al. 2014)

Pijat bayi merupakan terapi sentuhan dengan teknikteknik tertentu yang memiliki banyak manfaat. Beberapa manfaat lain dari pijat bayi terhadap perubahan fisiologis yang dapat diukur secara ilmiah antara lain melalui pengukuran kadar kartisol ludah, kartisol plasma secara Radioimunoassay, kadar hormone stress (Chatecholamine) air seni dan pemeriksaan EEG (Electro Enchepalogram), gambaran gelobang otak (Abdurrahman, 2015).

Pijat bayi sebagai terapi sentuhan memiliki banyak manfaat positif yang dapat mendukung bayi dan perkembangannya serta dapat menjadi terapi komplementer pada bayi dengan konstipasi. Pijat bayi memiliki manfaat untuk melancarkan sistem pecernaan bayi dan membantu bayi untuk relaksasi sehingga bayi tersebut merasa nyaman dan tidak rewel (Bennett, Underdown, and Barlow 2013).
Pijatan pada tubuh diyakini dapat menstimulasi sirkulasi darah lokal. Pembuluh darah pada daerah tubuh yang dipijat akan mengalami dilatasi dan aliran darah pada daerah yang dipijat meningkat. Peningkatan aliran darah dapat dinilai dengan membandingkan suhu dari daerah dalam pemijatan sebelum dan sesudah dilakukan pemijatan (Kadim and Endyarni 2016). Berdasarkan teori tersebut, diasumsikan bahwa dengan menstimulasi sirkulasi darah, maka dapat juga melancarkan peredaran darah ke organ pencernaan.

Pijat dapat merangsang sistem saraf dan hormon. Pijatan merupakan rangsangan taktil di permukaan kulit dan merangsang persarafan disekitarnya. Sel-sel saraf akan bekerja memberikan informasi ke otak, sehingga otak dapat menginstruksikan enzim ODC (ornithin decarboxylase) untuk meningkatkan produksinya. Enzim tersebut bekerja untuk menjadi petunjuk bagi pertumbuhan sel dan jaringan. Pertumbuhan sel dan jaringan bermanfaat untuk memperbaiki kondisi pencernaan yang rusak akibat invasi mikroorganisme (Suranto, 2011)

\section{KESIMPULAN}

Terdapat pengaruh pijat bayi terhadap konstipasi pada bayi usia 6-12 bulan yang diberikan terapi pijat dengan significancy.

\section{UCAPAN TERIMA KASIH}

Para dosen pembingbing dan seluruh civitas akademis di STIKES Widyagama Husada malang yang telah membantu proses penelitian ini. Selin itu Pihak Puskesmas Mojolangu Kota Malang, yang telah mengizinkan penelitian ini berlangsung.

\section{DAFTAR RUJUKAN}

Jurnalis YD, Sarmen S, Sayoeti Y. Konstipasi Pada Anak. CDK-200. 2013; 40(1):27-31

McClurg D, Lowe-Strong A. Does Abdominal Massage Relieve Constipation?. Nursing Times. 2011; 
107(12): 20-2.

Abdurrahman, S. M. (2015). Pengaruh Pijat Bayi

Terhadap Kualitas Tidur Bayi Di Desa Tabumela

Kecamatan Tilango Kabupaten Gorontalo. Jurnal

Keperawatan, 3(1), 1-18

"Amry RY. Analisis Faktor-Faktor Kejadian Konstipasi

Pada Lanjut Usia Di Panti Wredha Budhi Dharma

Umbulharjo Yogyakarta. Jurnal Ilmu Kesehatan

Volume 9. No. 2 Juli. Yogyakarta: Stikes Surya

Global; 2013. -

Bennett, Cathy, Angela Underdown, and Jane Barlow.

2013. "Massage for Promoting Mental and Physical

Health in Typically Developing Infants under the

Age of Six Months." Cochrane Database of Systematic Reviews 2013(4).

Claudina dkk. 2018. Hubungan Asupan Serat Makanan

Dan Cairan Dengan Kejadian Konstipasi

Fungsional Pada Remaja Di Sma Kesatrian 1

Semarang. JURNAL

KESEHATAN

MASYARAKAT (e-Journal) Volume 6, Nomor 1, Januari 2018 (ISSN: 2356-3346)

Iacono, G., Merolla R., D’Amico, D., Bonci, E., Cavatio,

F., Di Prima. (2010). Gastrointestinal Symptoms in Infants:A Population-Based Prospective Study. Dig Liver Dis; 37: 432.9

Kadim, Muzal, and Bernie Endyarni. 2016. "Manfaat Terapi Pijat Pada Konstipasi Kronis Anak.” Sari Pediatri 12(5): 342.

Mayriza Wulandari. (2016). Hubungan Antara Asupan

Serat Dengan Kejadian Konstipasi Pada Pekerja Di

PT.Tiga Serangkai Surakarta.

Syuarsyafl dkk. 2015. Pengaruh Terapi Pijat Terhadap
Konstipasi. Majority Volume 4 Nomor 9 Desember 2015

Setiawan. 2017. Perbedaan Kejadian Konstipasi Pada Bayi Usia 0-6 Bulan Yang Asi Ekslusif Dan Non Ekslusif. Oksitosin, Kebidanan, Vol. Iv, No. 2, Agustus 2017: 78-84

Rochsitasari N, Santosa B, Puruhita N. Perbedaan Frekuensi Defekasi Dan Konsistensi Tinja Bayi Sehat Usia 0-4 Bulan Yang Mendapat ASI Eksklusif, Non Eksklusif, Dan Susu Formula. Sari Pediatri. 2011; 13(3): 191-9.

Suranto A. Pijat Anak. Jakarta: Penebar Swadaya Grup; 2011.

Wang $\mathrm{X}$, Yin J. Complementary and Alternative Therapies for Chronic Constipation. EvidenceBased CAM. 2015; 2015(1): 1-11.

$\mathrm{Xu}$, Xiao $\mathrm{Hu}$ et al. 2014. "A Randomized Controlled Trial of Acupuncture to Treat Functional Constipation: Design and Protocol." BMC Complementary and Alternative Medicine 14(1): 423.

http://bmccomplementalternmed.biomedcentral.com /articles/10.1186/1472-6882-14-423 (March 12, 2021).

Zeevenhooven, Judith, Ilan J.N. Koppen, and Marc A. Benninga. 2017. "The New Rome IV Criteria for Functional Gastrointestinal Disorders in Infants and Toddlers.” Pediatric Gastroenterology, Hepatology and Nutrition 20(1): 1-13. 